Article

\title{
Fast Pyrolysis of Four Lignins from Different Isolation Processes Using Py-GC/MS
}

\author{
Xiaona Lin ${ }^{1}$, Shujuan Sui ${ }^{1}$, Shun Tan ${ }^{1}$, Charles U. Pittman, Jr. ${ }^{2}$, Jianping Sun ${ }^{1,3}$ and \\ Zhijun Zhang ${ }^{1, *}$
}

1 MOE Key Laboratory of Bio-based Material Science and Technology, Northeast Forestry University, Harbin 150040, Heilongjiang, China; E-Mails: linxiaona1120@163.com (X.L.); 15945180240@163.com (S.S.); shuntannefu@163.com (S.T.); sunjp1977@163.com (J.S.)

2 Department of Chemistry, Mississippi State University, Mississippi State, MS 39762, USA; E-Mail: cpittman@chemistry.msstate.edu

3 School of Municipal and Environmental Engineering, Shenyang Jianzhu University, Shenyang 110168, Liaoning, China

* Author to whom correspondence should be addressed; E-Mail: zzj_1003@163.com; Tel./Fax: +86-451-8219-1993.

Academic Editor: Thomas E. Amidon

Received: 6 April 2015 / Accepted: 22 May 2015 / Published: 1 June 2015

\begin{abstract}
Pyrolysis is a promising approach that is being investigated to convert lignin into higher value products including biofuels and phenolic chemicals. In this study, fast pyrolysis of four types of lignin, including milled Amur linden wood lignin (MWL), enzymatic hydrolysis corn stover lignin (EHL), wheat straw alkali lignin (AL) and wheat straw sulfonate lignin (SL), were performed using pyrolysis gas-chromatography/mass spectrometry (Py-GC/MS). Thermogravimetric analysis (TGA) showed that the four lignins exhibited widely different thermolysis behaviors. The four lignins had similar functional groups according to the FTIR analysis. Syringyl, guaiacyl and p-hydroxyphenylpropane structural units were broken down during pyrolysis. Fast pyrolysis product distributions from the four lignins depended strongly on the lignin origin and isolation process. Phenols were the most abundant pyrolysis products from MWL, EHL and AL. However, SL produced a large number of furan compounds and sulfur compounds originating from kraft pulping. The effects of pyrolysis temperature and time on the product distributions from corn stover EHL were also studied. At $350{ }^{\circ} \mathrm{C}$, EHL pyrolysis mainly produced acids and alcohols, while phenols became the main products at
\end{abstract}


higher temperature. No obvious influence of pyrolysis time was observed on EHL pyrolysis product distributions.

Keywords: lignin; fast pyrolysis; phenolic compounds; Py-GC/MS

\section{Introduction}

Concerns over future fossil fuel depletion and current global warming have led to an increasing interest in converting biomass into biofuels [1]. Biomass-derived fuels are renewable because the $\mathrm{CO}_{2}$ released from their combustion can be recycled into the replacement plants by photosynthesis [2]. Lignin is a major component of biomass. It is a three-dimensional amorphous polymer consisting of methoxylated phenylpropane structures [3]. It is the major renewable aromatic resource and its chemical structure and abundance varies with its source species [4]. Abundant industrial lignin is obtained as by-product from pulping and enzymatic hydrolysis or fermentation processes [5]. However, these lignin residues are disposed of as waste or burned to generate steam as a low-grade fuel. This is a low value use. A minor fraction is used to produce low value products such as dispersants and adhesives, while most lignin has not been used more profitably because of its complex structure [6]. Fast pyrolysis converts biomass into gas, liquid and solid biofuels using intermediate temperatures and short residence times in the absence of oxygen [7,8]. Lignin has a higher carbon and lower oxygen content than bulk plant (lignocellulosic) biomass, so fast pyrolysis may lead to biofuels with lower oxygen content or useful phenolic chemicals [9].

Thermogravimetric analysis (TGA) demonstrates that lignin is the most thermally resistant biomass organic component of plants, gradually decomposing over a wide temperature range of $300-800{ }^{\circ} \mathrm{C}[10,11]$. The relative composition and product distribution from pyrolysis depend on the heating rate, reaction temperature, residence time, plant species and age, isolation methods, etc. [12-14]. Generally, lignins from hardwoods contain guaiacyl- and syringyl-type compounds as major components, while lignins from softwoods only contain guaiacyl-typecompounds as major constitutes. Their pyrolysis products reflect this chemistry [15]. The pyrolysis of lignin is mainly a free-radical decomposition mechanism, leading to the formation of monomeric phenolic compounds [10].

Various types of lignin are derived from different isolation methods, such as Björkmann lignin, Klason lignin, Organosolv lignin and Alkali lignin [16]. The structure of milled wood lignin (MWL) isolated by the Björkmann method is considered to produce a product most similar to the native lignin verses the compositions of other extracted lignins [14]. Kraft lignin contains sulfur originating from Kraft pulping. This leads to the existence of sulfur compounds in Kraft lignin's pyrolytic products [17]. Lignin residue from ethanol production contains cellulose and hemicellulose degradation products.

Recently, Nowakowski et al. [18] demonstrated that the lignin feedstock's origin has a significant effect on the pyrolysis-derived bio-oil products. The lignin's thermal behavior and product yields vary with the process by which the lignin was derived. However, only one or two types of lignins were investigated in most publications [19]. This makes it difficult to compare data for different lignins because of the varying conditions use and analytic methods employed. Therefore, systematic investigations and comparisons of the pyrolysis behavior of various types of lignins could help to 
better understand the effects of both lignin separation method and origin on their pyrolysis behaviors. Additionally, Lignins from large industrial processes need to be targeted for detailed optimized fast pyrolysis studies to determine if specific process conditions can be identified to produce useful product fractions. In this study, the pyrolysis of four types of lignin obtained by different processes, including Amur linden lignin MWL, corn stover lignin EHL, wheat straw lignin AL and wheat straw lignin SL, were carried out using TGA and pyrolysis gas-chromatography/mass spectrometry. The differences in pyrolysis behavior and product distribution of the four lignins were investigated under the same pyrolytic conditions systematically. The effects of different pyrolysis temperatures and times on the product compositions of the EHL were also studied.

While the three biomass sources (Amur linden, corn stover and wheat straw lignins) chemically differ and the methods of isolation used also differ, we have not studied lignin thermolysis from each biomass source where the lignin was isolated by all four of the separation methods (Björkmann, EHL, $\mathrm{AL}$ and SL). Instead we have only used the commercially available sources of lignin. This was focus of this work rather than developing the isolation methods for each species.

\section{Results and Discussion}

\subsection{Thermogravimetric Analysis}

The TGA and derivative thermogravimetric analysis (DTG) curves of the four selected lignins are shown in Figure 1. The DTG curves' peak temperatures, and maximum decomposition rates and the TGA residue percents are given in Table 1 . When the temperature was $<120^{\circ} \mathrm{C}$, the weight loss of the four lignins involved free water evaporation. Most decomposition occurred over a wide temperature $150-500{ }^{\circ} \mathrm{C}$ range. There are two small DTG peaks between $200{ }^{\circ} \mathrm{C}$ and $250{ }^{\circ} \mathrm{C}$ in MWL, attributed to the loss of some gaseous products from the cleavage of lignin side chains [20]. Major decomposition of MWL occurred at higher temperatures. The MWL was isolated by the Björkmann method, which leaves the lignin less decomposed than other methods (and with the highest molecular wt.). Thus, it takes more total bond cleavages and bond breaking to vaporize MWL. This, in turn, requires higher temperatures. EHL has the lowest decomposition rate and lowest absolute weight loss, leading to the highest residue yield (57.8\%). The TGA of wheat straw AL also has a slow weight loss and about the same residue yield as corn stover EHL. The wheat straw AL has two major mass loss peaks appearing at $232{ }^{\circ} \mathrm{C}$ and $404{ }^{\circ} \mathrm{C}$. The fragmentation of many major chain linkages occurred between $150-300{ }^{\circ} \mathrm{C}$ and the residue further reacted to form char in the temperature range from 350 to $500{ }^{\circ} \mathrm{C}$. The low decomposition temperature of wheat straw AL was most likely promoted by the catalytic effect of sodium derived from the isolation process [21]. The Wheat Straw SL lignin shows a vast weight decrease at relatively low temperatures due to its high sulfur and carboxylic group content, which can both readily decompose to form gases (e.g., $\mathrm{SO}_{2}$ and $\mathrm{CO}_{2}$ ). These four lignin types displayed markedly different thermal degradation behaviors, a result of their different structures and compositions when isolated by different processes. 

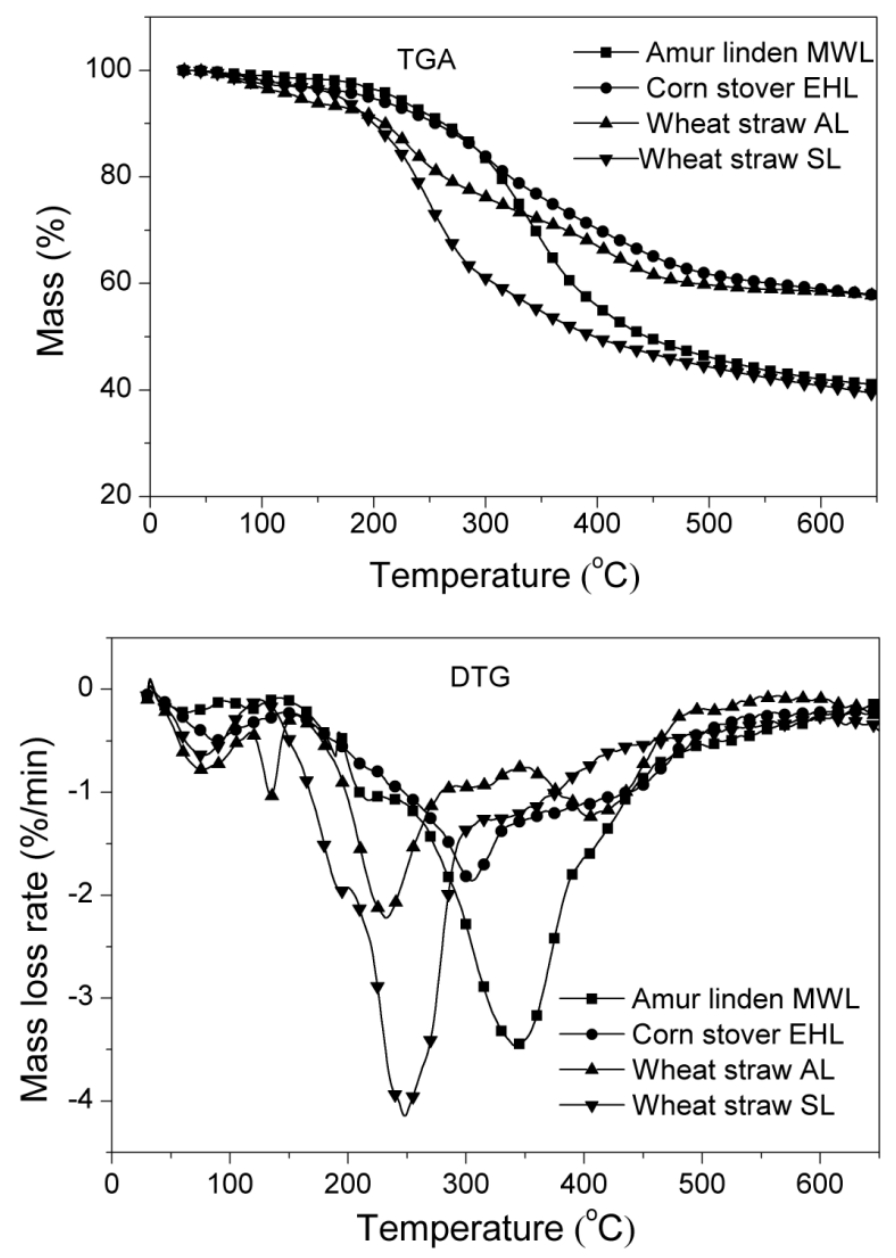

Figure 1. Curves of TGA and DTG for four different lignins, all at a heating rate of $10{ }^{\circ} \mathrm{C} / \mathrm{min}$. MWL: milled wood lignin; EHL: enzymatic hydrolysis lignin; AL: alkali lignin; SL: sulfonate lignin.

Table 1. Characteristic points on the TGA and DTG curves of the four lignins used in pyrolysis studies.

\begin{tabular}{cccc}
\hline Lignin $^{\mathbf{a}}$ & $\mathbf{T}_{\boldsymbol{\operatorname { m a x }}}{ }^{\mathbf{b}}\left({ }^{\circ} \mathbf{C}\right)$ & $\mathbf{M D R}^{\mathbf{c}}\left({ }^{\circ} \mathbf{C} / \mathbf{m i n}\right)$ & Residue (\%) \\
\hline MWL & 342 & 3.5 & 41.0 \\
$\mathrm{EHL}$ & 305 & 1.9 & 57.8 \\
$\mathrm{AL}$ & 232 & 2.2 & 57.6 \\
$\mathrm{SL}$ & 248 & 4.1 & 39.2 \\
\hline
\end{tabular}

${ }^{a}$ MWL: milled Amur linden wood lignin; EHL: enzymatic hydrolysis corn stover lignin; AL: alkali lignin from wheat straw black liquor; SL: sulfonate lignin from wheat straw black liquor. ${ }^{\mathrm{b}}$ The peak temperature of DTG curve. This is where the mass loss occurs at the highest rate under the DTG conditions used. ${ }^{\mathrm{c}}$ The maximum decomposition rate.

\subsection{FTIR Analysis}

The FTIR spectra of the four lignins and their pyrolytic residues are presented in Figure 2, and their main adsorption peaks are assigned in Table 2. All four lignins exhibited similar characteristic absorptions for the functional groups identified in Figure 2. Hydroxyl (3571-3037 $\left.\mathrm{cm}^{-1}\right)$, methoxyl 
$\left(1210 \mathrm{~cm}^{-1}, 1028 \mathrm{~cm}^{-1}\right)$ and aromatic ring $\left(1600,1515\right.$ and $\left.1420 \mathrm{~cm}^{-1}\right)$ vibration bands are present in all four lignins. However, the aromatic ring absorption peaks in AL exhibited higher intensities than those in the other three lignins. The MWL absorption peaks in fingerprint region were the most abundant and its non-conjugated carbonyl absorption at $1710 \mathrm{~cm}^{-1}$ was detected. MWL exhibited the highest molecular weight $(18,000$, Table 3$)$, in agreement with this lignin having a structure closer to what occurs in the plant. Thus, one would expect more of the aliphatic regions between aromatics rings would survive. MWL also showed the strongest sp3 C-H stretching absorptions at 2932 and $2835 \mathrm{~cm}^{-1}$ among the four types of lignin, in accord with this view. This suggests that MWL might generate more hydrocarbons during pyrolysis [9]. The FTIR spectrum of EHL was similar that of MWL, but the absorption peaks were weaker from $1700 \mathrm{~cm}^{-1}$ to $1250 \mathrm{~cm}^{-1}$. A broad-absorptive band was found between $1180 \mathrm{~cm}^{-1}$ and $880 \mathrm{~cm}^{-1}$ in EHL, and two broad bands appeared in AL at $1527-1241 \mathrm{~cm}^{-1}$ and $1190-910 \mathrm{~cm}^{-1}$. These broad bands occur due to the overlap of many different peaks. The $\mathrm{S}=\mathrm{O}$ symmetric stretching vibration was found at $1030 \mathrm{~cm}^{-1}$ in the spectrum of SL. The FTIR spectra of the pyrolytic residues of all four lignins are shown in Figure 2. The intensities of most absorption peaks are weakened, indicating that many syringyl, guaiacyl and p-hydroxyphenylpropane structural units and the three carbon units connecting such units into the lignin crosslinked structure were broken down in pyrolysis.
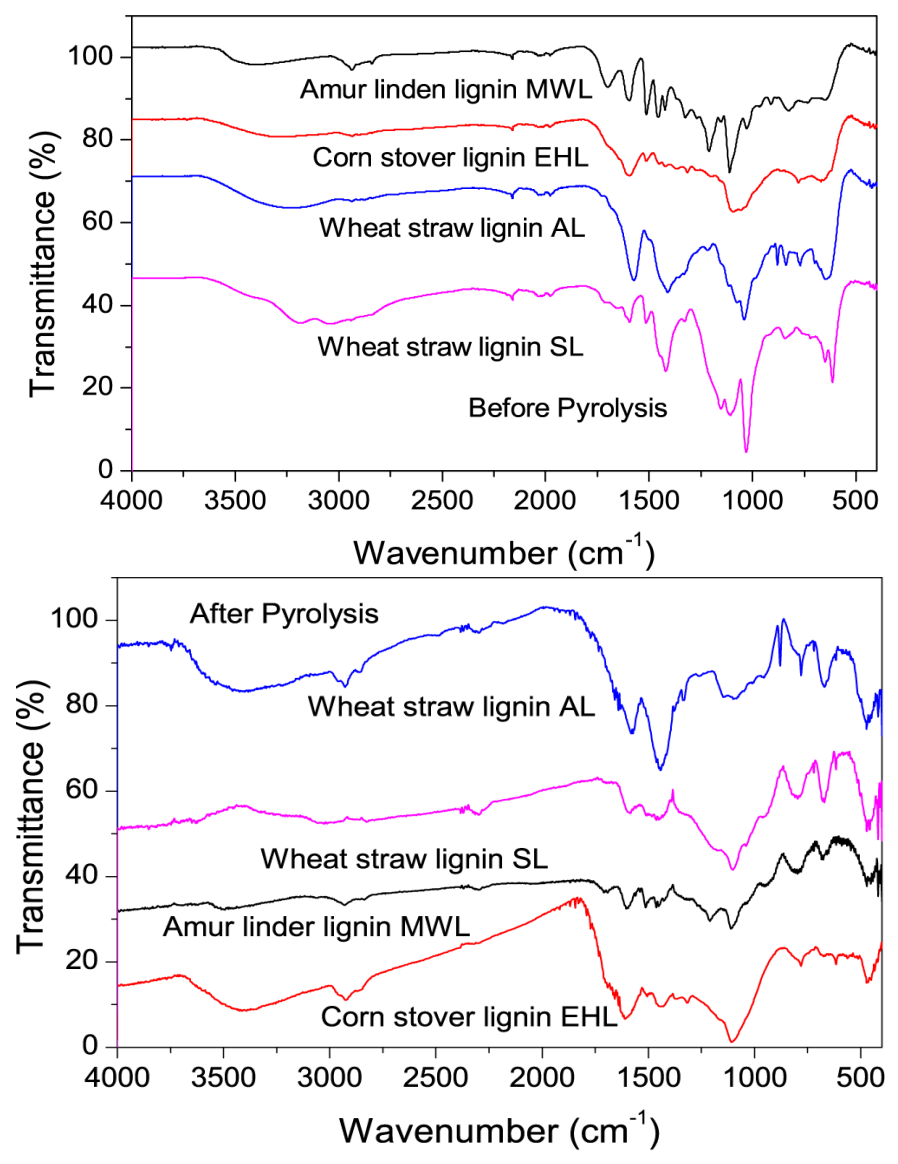

Figure 2. FTIR spectra of the four lignins before and after pyrolysis. MWL: Amur linden milled wood lignin; EHL: corn stover enzymatic hydrolysis lignin; AL: wheat straw alkali lignin; SL: wheat straw sulfonate lignin. 
Table 2. The FTIR analysis of lignin microstructure.

\begin{tabular}{cc}
\hline Wave number $\left(\mathbf{c m}^{-1}\right)$ & Band origin \\
\hline 2932,2835 & $\mathrm{C}-\mathrm{H}$ stretching vibrations of alkyls \\
1710 & $\mathrm{C}=\mathrm{O}$ non-conjugate stretching vibration \\
1600 & $\mathrm{C}=\mathrm{O}$ stretching vibration conjugated to the aromatic ring, aromatic ring vibration \\
1510 & Aromatic ring vibrations \\
1455 & $\mathrm{C}-\mathrm{H}$ bending vibration, asymmetric vibration of $\mathrm{CH}_{3}$ and $\mathrm{CH}_{2}$ \\
1420 & Aromatic ring vibrations and $\mathrm{C}-\mathrm{H}$ in plane deformation \\
1322 & Syringyl ring and $\mathrm{C}-\mathrm{O}$ stretching vibration \\
1270 & Guaiacyl ring and $\mathrm{C}-\mathrm{O}$ stretching vibration \\
1210 & $\mathrm{C}-\mathrm{C}$ and $\mathrm{C}-\mathrm{O}$ stretching vibrations \\
1148 & $\mathrm{C}-\mathrm{H}$ in plane deformations of guaiacyl units \\
1108 & $\mathrm{C}-\mathrm{H}$ in plane deformations of syringyl units \\
1028 & $\mathrm{C}-\mathrm{H}$ in plane deformation of aromatic ring, $\mathrm{S}=\mathrm{O}$ symmetrical stretching vibration \\
910 & $\mathrm{C}-\mathrm{H}$ out-of-plane deformation of aromatic ring \\
836 & $\mathrm{C}-\mathrm{H}$ out-of-plane in positions 2 and 6 of syringyl units \\
827 & $\mathrm{C}-\mathrm{H}$ out-of-plane in positions 2, 5 and 6 of guaiacyl units \\
\hline
\end{tabular}

\subsection{Results of $P y-G C / M S$}

\subsubsection{Pyrolysis of the Four Lignins}

Pyrolyses of all lignins were carried out using Py-GC/MS at $450{ }^{\circ} \mathrm{C}$ with a $30 \mathrm{~s}$ pyrolysis time. Since the heating rate was $20^{\circ} \mathrm{C} / \mathrm{ms}$, only $21-22 \mathrm{~ms}$ are required for a sample to reach $450{ }^{\circ} \mathrm{C}$ from room temperature. Thus, for essentially all $30 \mathrm{~s}$ the sample experiences $450{ }^{\circ} \mathrm{C}$. The detected products can be roughly classified into acids, alcohols, aldehydes, ketones, furans, phenols, esters and hydrocarbons as summarized in Figure 3a. Phenols are the most abundant products among the MWL, EHL and AL pyrolysis products, and the second most abundant group for SL. Large numbers of furans and sulfur compounds are formed in the pyrolysis of SL. Furans are the most abundant products from SL. The highest phenolic content, 58.4 area \% of all GC peaks, was obtained from AL pyrolysis. This was consistent with the FTIR analysis, which showed the most intense adsorption peaks associated with aromatic ring vibrations (1600 and $\left.1420 \mathrm{~cm}^{-1}\right)$ and $\mathrm{C}-\mathrm{H}$ out-of-plane deformations of aromatic rings at $800-900 \mathrm{~cm}^{-1}$. Amen-Chen et al. [22] and Zakzeski et al. [23] suggested that free-radical depolymerization/fragmentation reactions during lignin pyrolysis resulted in monomeric phenolic compound formation. 

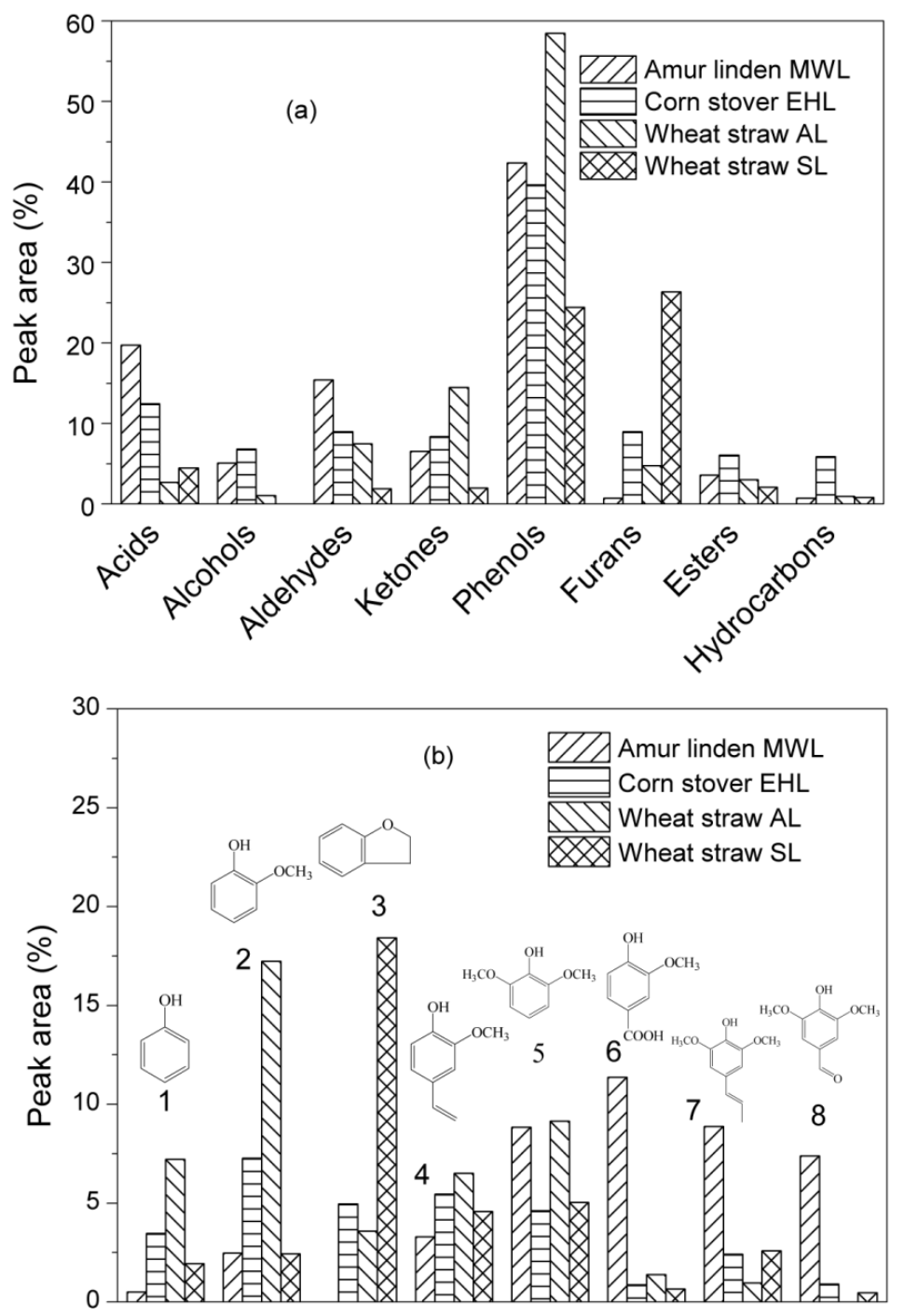

Figure 3. (a) Comparison of the product distributions from the pyrolysis of the four lignins. (b) Specific typical compounds produced by pyrolyzing the four lignins. MWL: milled wood lignin; EHL: enzymatic hydrolysis lignin; AL: alkali lignin; SL: sulfonate lignin.

The composition and distribution of phenolic products are influenced by the types of lignin as readily illustrated in Figure 3b. Guaiacyl (G)- and syringyl (S)-type compounds were the predominant products of Amur linden MWL, and the peak area ratio of G/S was 1.1. Small amounts of phenol and alkyl phenols were identified in MWL pyrolysis products indicating that few methoxyl groups were removed from the lignin monomeric unit at $450{ }^{\circ} \mathrm{C}$. The main Guaiacyl- and syringyl-type products were 2-methoxyphenol, 2-methoxy-4-vinylphenol, 4-hydroxy-3-methoxybenzoic acid, 2,6-dimethoxyphenol, 2,6-dimethoxy-4-(2-propenyl)phenol and 4-hydroxy-3,5-dimethoxybenzaldehyde as shown in Figure $3 b$. Other guaiacyl- and syringyl-type compounds were also observed, such as 2-methoxy-4methylphenol, 4-ethyl-2-methoxyphenol, eugenol, vanillin, 2-methoxy-4-(1-propenyl)phenol and 1-(4-hydroxy-3,5-dimethoxyphenyl)ethanone. As expected, the guaiacyl-, syringyl- and p-hydroxyphenyl-type $(\mathrm{H})$ compounds were all identified in the products of corn stover EHL and wheat stalk AL and wheat stalk SL. The peak area ratio of $\mathrm{G} / \mathrm{S} / \mathrm{H}$ was 1.7/1/0.8 for EHL, 2.3/1/0.9 for $\mathrm{AL}$ and $0.8 / 1 / 0.4$ for SL. The primary H-type products were 4-methylphenol and 4-ethylphenol. 
Guaiacyl-type compounds were the most abundant phenols in the AL pyrolysate, accounting for 31.1\% of the total peak area. However, in SL pyrolysis products, the total peak area of syringyl-type compounds was slightly higher than those of guaiacyl-tpye compounds. Above all, it is clear that the fast pyrolysis products depend strongly on the lignin's origin and isolation process.

The yield of furans in the SL pyrolysate was higher, up to $26.3 \%$, than for the other three lignins. 2,3-Dihydrobenzofuran was the most abundant furan accounting for $18.4 \%$. According to Lou et al. [24], the lignin pyrolysis mechanism proceeds through an o-quinonemethide intermediate with an allylmethyl group. This intermediate then cyclized followed by hydrogen abstraction to produce 2,3-dihydrobenzofuran. Furan compounds such as furfural and 5-methoxy-2-furancarboxaldehyde are well known to arise from the pyrolysis of cellulose and hemicellulose or their oligomers. These constituents were found in EHL, AL and SL, confirming that these three feedstocks were not pure lignins. Levoglucosan was identified in the EHL, AL and SL pyrolysis products $(1.4 \%, 0.9 \%$, and $0.3 \%$, respectively), which confirmed this point.

MWL generated the largest amounts of acids and aldehydes indicating the presence of large amounts of carbonyl functions in MWL. This is in good agreement with the relatively higher adsorption in about $1710 \mathrm{~cm}^{-1}$ (characteristic absorption of $\mathrm{C}=\mathrm{O}$ stretching vibration) in FTIR spectrum of MWL. Moreover, the peak areas of 4-hydroxy-3-methoxybenzoic acid (11.3\%), 4-hydroxy-3,5-dimethoxybenzaldehyde (7.4\%), and vanillin (3.3\%) in MWL pyrolysate were significantly higher than those in other three lignins. This further agrees with our postulate that large amounts of carbonyl and carboxyl functional groups were present in the structure of MWL. Acetic acid and aldehydes (mainly acetaldehyde) detected in the pyrolysate of four lignins were derived from the side-chain cleavage from lignin as well as the decomposition of residual cellulose, hemicellulose or their oligomers remaining in the lignin. AL had the highest ketone yield, composed mainly of 2-hydroxy-3-methyl-2-cyclopenten-1-one, 2-methyl-2-cyclopenten-1-one and 2-butanone. Large amounts of sulfur-containing compounds including sulfur dioxide, methanethiol, carbon disulfide and dimethyl sulfide were detected in the pyrolysis products of SL. The yield of methanethiol in SL pyrolysate reached $14.0 \mathrm{GC}$ area \%. These sulfur-containing compounds may originate during kraft pulping as well as from thermochemical reactions occurring during pyrolysis [25]. Pyrolysis char residues have higher $\mathrm{C} / \mathrm{H}$ ratios than the original lignins (Table 3), indicating the degree of carbonization of lignin that occurred during its pyrolysis.

\subsubsection{The Effects of Pyrolysis Temperature and Time}

The effect of different pyrolysis temperatures $\left(350,450,550\right.$ and $\left.650{ }^{\circ} \mathrm{C}\right)$ on the corn stover EHL product compositions and distributions was studied. The pyrolysis products derived from EHL were classified into eight categories: acids, alcohols, aldehydes, ketones, phenols, furans, esters and hydrocarbons as given in Figure 4a. At $350{ }^{\circ} \mathrm{C}$, EHL pyrolysis mainly produced alcohols and acids including 5.1\% acetic acid, 14.1\% 2-hydroxypropanoic acid, 3.4\% 2-octanol, 4.8\% glycerin and 2.3\% 1,2,3-butanetriol (in GC area percents). These products were mainly derived from the pyrolysis of cellulose, hemicellulose and the side-chain cleavages from lignin's guaiacyl rings. The yields of acids and alcohols decreased as the pyrolysis temperature increased. Ben et al. also found that the concentration of acetic acid and methanol in light oil produced by lignin pyrolysis decreased as 
temperature rose [26]. The $13.3 \%$ yield of phenols indicated that only a fraction of the EHL decomposition pathway occurred at $350{ }^{\circ} \mathrm{C}$. At higher temperature $\left(450{ }^{\circ} \mathrm{C}\right)$, the amounts of phenolic compounds increased from $13.3 \%$ to $40.0 \%$ as greater structural fragmentation occurred. The yields of some typical phenols varied using different pyrolysis temperatures as shown in Figure $4 \mathrm{~b}$. All phenolic products increased distinctly as the temperature increased from $350{ }^{\circ} \mathrm{C}$ to $450{ }^{\circ} \mathrm{C}$. This demonstrated that more $\beta-\mathrm{O}-4, \alpha-\mathrm{O}-4, \mathrm{C}-\mathrm{C}$ lignin linkages were cracked to produce a large amount of single ring phenolic structures at higher temperature. As $550{ }^{\circ} \mathrm{C}$, the amount of phenols slightly decreased. The yields of aldehydes, ketones and furans rose in contrast to acids and alcohols at higher temperatures. These results are similar to the report of Lou et al. [13]. He found that the lower temperature $\left(250-400{ }^{\circ} \mathrm{C}\right)$ pyrolysis products of enzymatic/mild acidolysis lignin were mainly 2,3-dihydrobenzofuran, while at $400-800^{\circ} \mathrm{C}$, phenols were the main products.
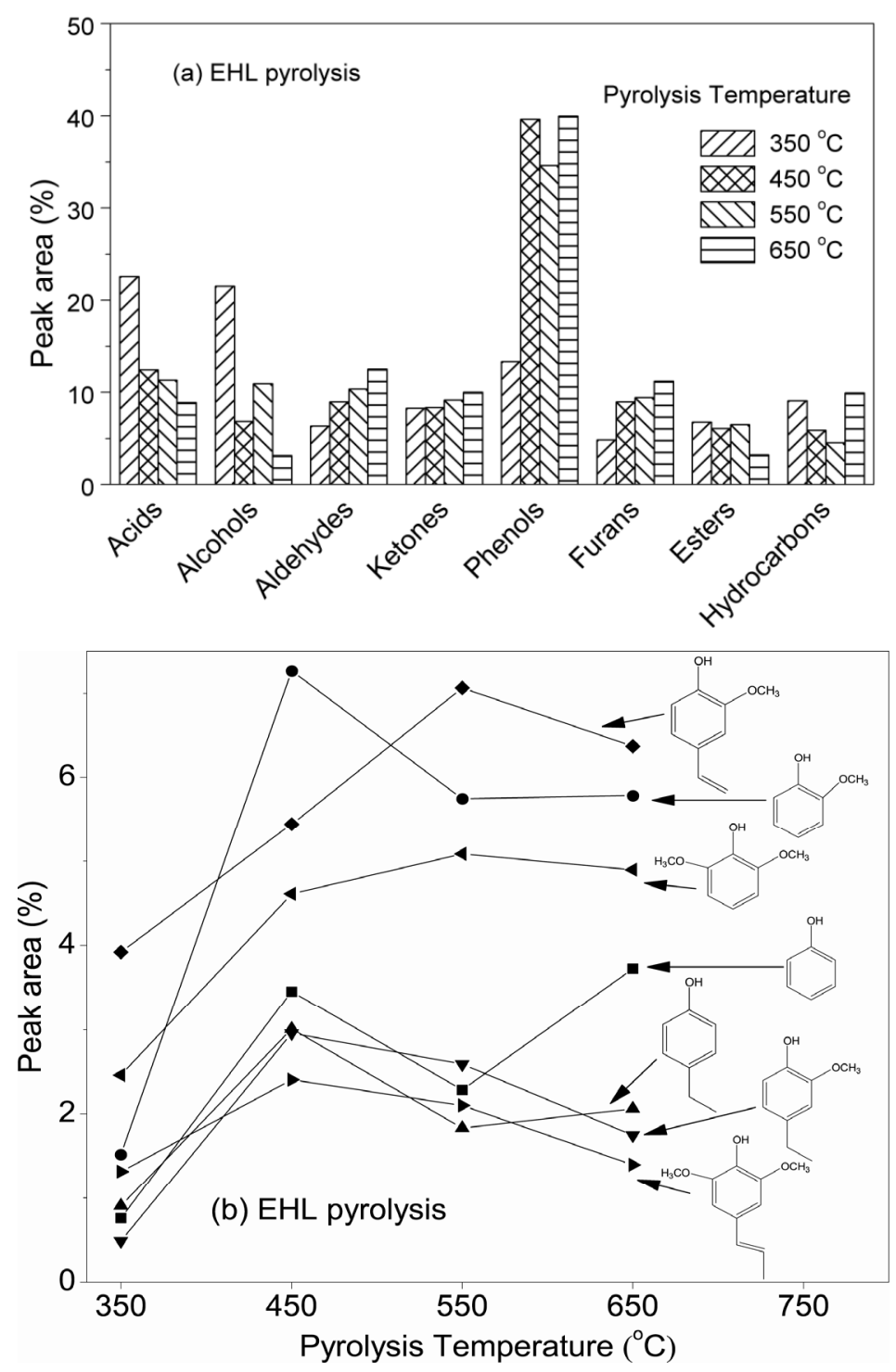

Figure 4. (a) Comparison of the product distributions. (b) typical compounds from corn stover EHL pyrolysis at different temperatures. The pyrolysis time holding for $30 \mathrm{~s}$. 匹: phenol, •: 2-methoxyphenol, $\boldsymbol{\Delta}$ : 4-ethylphenol, $\boldsymbol{\nabla}$ : 4-ethyl-2-methoxyphenol, ४: 2-methoxy-4-vinylphenol, ४: 2,6-dimethoxyphenol, \: 2,6-dimethoxy-4-(2propenyl)phenol. 
The influence of pyrolysis time $(15,30$ and $60 \mathrm{~s})$ at $450{ }^{\circ} \mathrm{C}$ on corn stover EHL was also studied. As presented in Figure 5, pyrolysis time had little effect on product distribution. The yields of aldehydes, ketones, furans, esters and hydrocarbons fluctuated verses pyrolysis times within a fairly narrow range. Alcohol production increased to $15.5 \%$ going from $30 \mathrm{~s}$ to $60 \mathrm{~s}$. The maximum yield of phenols occurred in $30 \mathrm{~s}$.

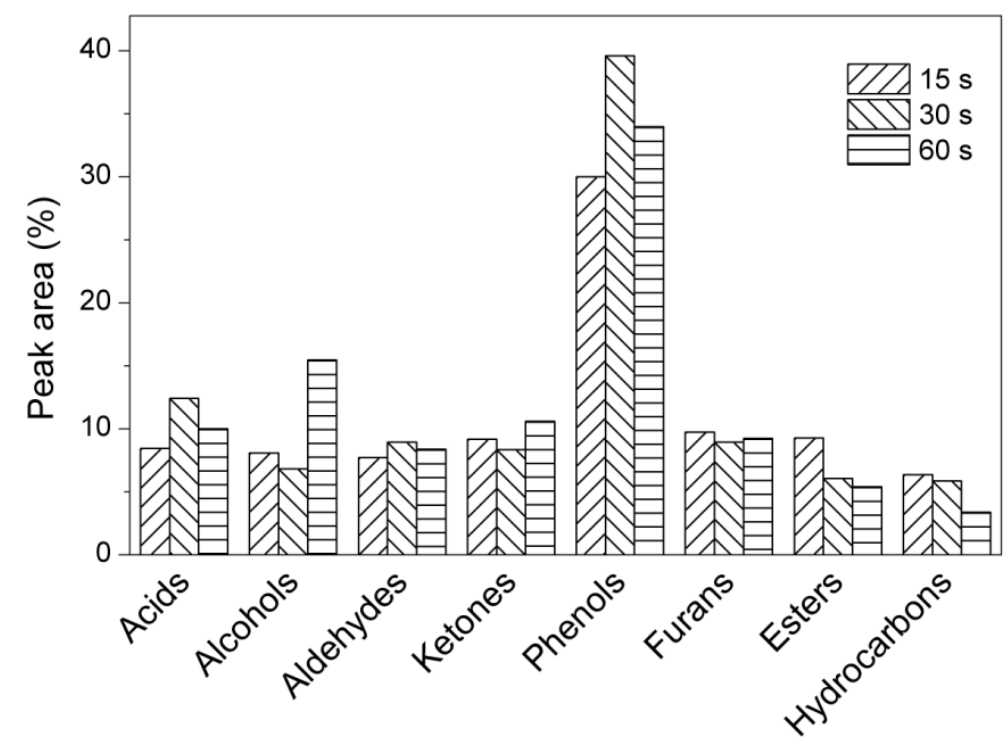

Figure 5. The effect of pyrolysis times from 15 to $60 \mathrm{~s}$ at $450{ }^{\circ} \mathrm{C}$ on the product distributions of corn stover EHL pyrolysis.

\subsection{Comparability between TGA and Py-GC/MS}

It is well known that the weight loss behavior and product composition depend on the lignin isolation processes. In this study, TGA was used to determine degradation behaviors of the four lignins. Py-GC/MS was used to detect the product compositions of the four lignins. TGA and Py-GC/MS are not directly comparable because of the significantly differences of sample dosage and heating rates. Different sample dosages and heating rates would play different effects on both heat and mass transfer rate which would clearly produce different and varying product distributions. Actually, we studied the effect of heating rate on the pyrolysis product composition of EHL. The peak area \% of phenols and carbonyls were decreased while the peak area $\%$ of acids, esters and aromatics were slightly increased with the heating rate decrease from $20^{\circ} \mathrm{C} / \mathrm{ms}$ to $2{ }^{\circ} \mathrm{C} / \mathrm{s}$. It indicated that different heating rates result in different product distribution.

Table 3. Comparison char yields by using Py-GC/MS and TGA at $450{ }^{\circ} \mathrm{C}$ a

\begin{tabular}{ccc}
\hline \multirow{2}{*}{ Lignin sample } & \multicolumn{2}{c}{ Char yield (\%) } \\
\cline { 2 - 3 } & Py-GC/MS & TGA \\
\hline MWL & 52.2 & 49.5 \\
EHL & 66.7 & 65.1 \\
AL & 62.7 & 61.7 \\
SL & 45.2 & 46.7 \\
\hline
\end{tabular}

a The heating rates of Py-GC/MS and TGA are $20{ }^{\circ} \mathrm{C} / \mathrm{ms}$ and $10^{\circ} \mathrm{C} / \mathrm{min}$, respectively. 
Table 3 shows the comparison of char yields obtained separately by Py-GC/MS and TGA at the same pyrolysis temperature $\left(450^{\circ} \mathrm{C}\right)$. We can see from Table 3 that, weight losses from Py-GC/MS and TGA, which employed both varying sample dosages and heating rates, show a close relationship. This implies that weight loss from the TG analysis would be reflected in the fast pyrolysis to a considerable extent. In fact, extent of this rather close correspondence is rather surprising given the enormous differences in heating rates.

\section{Experimental Section}

\subsection{Materials}

Milled wood lignin was isolated after extensive milling of Amur linden (Tilia amurensis Rupr.) wood flour in a ball mill prior to extraction with dioxane-water according to the Björkmann method [27]. Enzymatic hydrolysis lignin, provided by Tianguan Company (Henan, China), was extracted from corn stover residue, a byproduct derived from the production of bioethanol. We didn't determine the content of protein in enzymatic hydrolysis corn stover lignin (EHL). But, cellulose-isolated lignin is known to have protein impurities. The higher nitrogen content of EHL (1.1\%) versus the other lignins $(0.5-0.8 \%)$ determined by an elemental analyzer agrees with the existence of some nitrogenous compounds, protein most likely. Both alkali lignin (AL) and sulfonate lignin (SL) were purchased from Feihuang Chemical Company (Xinyin, China). AL was produced by treating the wheat straw black liquor from the $\mathrm{NaOH}$ pulping process with acid. SL was recovered from the spent wheat straw pulping liquids (red or brown liquor) from sulfite pulping. The four original lignins are characterized in Table 4. All the four types of lignin were used for experiments without further treatment except drying to constant weight at $105^{\circ} \mathrm{C}$.

Table 4. Characterization of the four lignin types used for pyrolysis.

\begin{tabular}{|c|c|c|c|c|}
\hline \multirow[t]{2}{*}{ Analyses } & \multicolumn{4}{|c|}{ Lignin ${ }^{a}$} \\
\hline & MWL & EHL & $\mathbf{A L}$ & SL \\
\hline Average Mol. Wt. & 18,000 & 1,200 & 9,000 & 5,400 \\
\hline Ash content (\%) & $<0.1$ & $<3.0$ & 13.1 & 11.8 \\
\hline Particle size (Mesh) & 120 & 120 & 120 & 120 \\
\hline Residual sugar (\%) & $<0.5$ & $<5.0$ & $\mathrm{UT}^{\mathrm{b}}$ & $\mathrm{UT}^{\mathrm{b}}$ \\
\hline $\mathrm{C}(\%)$ & 58.1 & 60.5 & 31.0 & 19.4 \\
\hline $\mathrm{H}(\%)$ & 5.7 & 6.5 & 4.4 & 3.2 \\
\hline $\mathrm{O}(\%)^{\mathrm{c}}$ & 35.7 & 31.9 & 64.0 & 71.0 \\
\hline $\mathrm{N}(\%)$ & 0.5 & 1.1 & 0.6 & 0.8 \\
\hline S (\%) & 0 & 0 & 0 & 5.6 \\
\hline $\mathrm{C} / \mathrm{H}$ ratio $^{\mathrm{d}}$ & $0.9(\mathbf{1 . 0})$ & $0.9(\mathbf{1 . 4 )}$ & $0.6(\mathbf{0 . 7 )}$ & $0.5(\mathbf{0 . 8})$ \\
\hline $\mathrm{O} / \mathrm{C}^{\text {ratio }^{\mathrm{e}}}$ & $0.6(6.4)$ & $0.5(\mathbf{3 . 1})$ & $2.1(5.1)$ & 3.7 (11.3) \\
\hline
\end{tabular}

\footnotetext{
${ }^{a}$ MWL: milled Amur linden wood lignin; EHL: enzymatic hydrolysis corn stover lignin; AL: alkali lignin from wheat straw black liquor; SL: sulfonate lignin from wheat straw black liquor. ${ }^{b}$ Untested. ${ }^{\mathrm{c}}$ Determined by difference. ${ }^{\mathrm{d}}$ The corresponding $\mathrm{C} / \mathrm{H}$ ratios of the four lignins after pyrolysis at $450{ }^{\circ} \mathrm{C}$ for $30 \mathrm{~s}$ are shown in parentheses as bold type. ${ }^{e}$ The corresponding $\mathrm{O} / \mathrm{H}$ ratios of the four lignins after pyrolysis at $450{ }^{\circ} \mathrm{C}$ for $30 \mathrm{~s}$ are shown in parentheses as bold type.
} 


\subsection{Methods}

The carbon, hydrogen, nitrogen and sulfur content of the samples were determined using an elemental analyzer (Flash EA 1112, Thermo Electron SPA, Waltham, MA, USA). The thermogravimetric behaviors of four lignins were performed in a thermogravimetric analyzer manufactured by Perkin-Elmer Company. TGA samples were heated from room temperature to $650{ }^{\circ} \mathrm{C}$ at a heating rate of $10^{\circ} \mathrm{C} / \mathrm{min}$ under nitrogen (99.99\%). The main chemical functional groups of these four lignins were analyzed by Nicolet6700 FTIR spectroscopy (Thermo Fisher Nicolet, Waltham, MA, USA) with high performance diamond ATR. Their pyrolytic residues were characterized using a MAGNA-IR560E.S.P. FTIR spectrometer (Nicolet Instr., Madison, WI, USA) in KBr pellets, between $400-4000 \mathrm{~cm}^{-1}$ at a resolution of $4 \mathrm{~cm}^{-1}$.

Fast pyrolysis experiments were carried out in a CDS 5200 pyroprobe directly connected to an Agilent $6890 \mathrm{~N}$ gas chromatograph (GC) mated to an Agilent 5973i mass spectrometer (MS). Samples $(0.5 \mathrm{mg})$ were placed in quartz tube and between quartz wool packed on each side and then the tubes were inserted into the pyroprobe. The sample in the pyroprobe was pyrolysed at a set point temperature range between $350{ }^{\circ} \mathrm{C}$ and $650{ }^{\circ} \mathrm{C}$ at a ramp rate of $20{ }^{\circ} \mathrm{C} / \mathrm{ms}$ with the final dwell time of $30 \mathrm{~s}$. The pyroprobe was operated in trap mode under a He atmosphere. The valve oven and transfer lines were maintained at 300 and $285{ }^{\circ} \mathrm{C}$, respectively. Separation of volatile pyrolysis products was achieved on an Agilent DB-17ms capillary column (30 $\mathrm{m} \times 0.25 \mathrm{~mm} \times 0.25 \mu \mathrm{m}$ film thickness). The split ratio was 50:1 with helium carrier gas flow of $1 \mathrm{~mL} / \mathrm{min}$. The $\mathrm{GC}$ oven temperature was held at $40{ }^{\circ} \mathrm{C}$ for $4 \mathrm{~min}$ and then programmed to $230{ }^{\circ} \mathrm{C}(2 \mathrm{~min})$ at $5{ }^{\circ} \mathrm{C} / \mathrm{min}$, and then heated further to $280{ }^{\circ} \mathrm{C}(5 \mathrm{~min})$ at $10^{\circ} \mathrm{C} / \mathrm{min}$. The mass spectrometer was operated in EI mode at $70 \mathrm{eV}$ over the $\mathrm{m} / \mathrm{z}$ range from 40 to $500 \mathrm{amu}$. The ion source was kept at $230{ }^{\circ} \mathrm{C}$. The inlet and auxiliary lines were both maintained at $300{ }^{\circ} \mathrm{C}$. Peak identification was carried out using both the NIST mass spectral library and relevant literature. Pyrolytic experiments were replicated two times under identical conditions, including using the same controlled amounts. The total iron chromatograms exhibited good reproducibility. The average values were used in plots of Py-GC/MS figures and standard deviations were less than 0.2.

\section{Conclusions}

The four lignins studied exhibited widely different thermal degradation behaviors at both slow and fast heating rates. The maximum weight loss rate regions in DTG were especially different and distinct. It is attributed to the different chemical structures of the lignins isolated by different processes. The same characteristic FTIR absorptions for the main lignin functional groups including both $\mathrm{sp}^{2}$ and $\mathrm{sp}^{3} \mathrm{C}-\mathrm{O},-\mathrm{OH}$ and aromatic ring breathing vibration were all identified in the four lignins, although with different intensities. The syringyl, guaiacyl and p-hydroxyphenyl structural units were partially broken down after pyrolysis.

The fast pyrolysis volatile products depend strongly on the lignin origin and isolation process. Phenols are the predominant products in the four lignins except for wheat straw SL which produces furans as the major products and large amounts of sulfur-containing compounds originating from kraft pulping. Corn stover MWL exhibited a guaiacyl-syringyl structure with the G/S peak area ratio of 1.1. Other three lignins exhibited guaiacyl-syringyl-p-hydroxyphenylstructure with different $\mathrm{G} / \mathrm{S} / \mathrm{H}$ ratios. 
Pyrolysis of corn stover-derived EHL at lower temperature $\left(350{ }^{\circ} \mathrm{C}\right)$ mainly caused side-chain cleavage to produce abundant acids and alcohols while at higher temperature $\left(\geq 450{ }^{\circ} \mathrm{C}\right)$ phenolic compounds became the predominant products. Pyrolysis time has no obvious effect on the EHL pyrolysis product distribution.

This work represents a first step in understanding how fast pyrolysis could be used to optimize product distribution ranges for isolation and further use or for upgrading. A thorough study of pyrolysis heating rates, temperatures and holding periods is needed at both atmospheric pressure and under vacuum to further explore the potential of various commercial lignins. Huge amounts of various types of lignin from different plant species are available. Each species is unique and each lignin isolation process is different. Hence, lignins from large industrial processes need to be targeted for detailed optimized fast pyrolysis studies to determine if specific process conditions can be identified to produce useful product fractions. Mixtures of products in all fractions are likely. Fast pyrolytic co-thermolysis of lignin with other organic feeds (waste polymers, bio-oil, hydeocarbon fractions, etc.), both in the presence and absence of catalysts, are future challenges.

\section{Acknowledgments}

This material is based upon work performed at the MOE Key Laboratory of Bio-based Material Science and Technology at Northeast Forestry University. This work was supported by the Fundamental Research Funds for the Central Universities under the Project Number 2572015BB02, and by the Academic Research Fund Project of Education Bureau of Liaoning Province, China (No.12012209). Mississippi State University supported Charles U. Pittman Jr.'s contribution to this work.

\section{Author Contributions}

Shu-juan Sui and Zhi-jun Zhang conceived and designed the experiments; Xiao-na Lin performed the experiments and wrote the paper; Shun Tan and Jian-ping Sun analyzed the data; Charles U. Pittman Jr. polished the article.

\section{Conflicts of Interest}

The authors declare no conflict of interest.

\section{References}

1. Butler, E.; Devlin, G.; Meier, D.; McDonnell, K. A rellview of recent laboratory research and commercial developments in fast pyrolysis and upgrading. Renew. Sust. Energ. Rev. 2011, 15, 4171-4186.

2. Zhang, Q.; Chang, J.; Wang, T.J.; Xu, Y. Review of biomass pyrolysis oil properties and upgrading research. Energy Convers. Manag. 2007, 48, 87-92.

3. Chakar, F.S.; Ragauskas, A.J. Review of current and future softwood kraft lignin process chemistry. Ind. Crop. Prod. 2004, 20, 131-141.

4. Mu, W.; Ben, H.; Ragauskas, A.; Deng, Y. Lignin Pyrolysis Components and Upgrading-Technology Review. Bioenerg. Res. 2013, 6, 1183-1204. 
5. Windt, M.; Meier, D.; Marsman, J.H.; Heeres, H.J.; de Koning, S. Micro-pyrolysis of technical lignins in a new modular rig and product analysis by GC-MS/FID and GC $\times$ GC-TOFMS/FID. J. Anal. Appl. Pyrolysis 2009, 85, 38-46.

6. Brebu, M.; Cazacu, G.; Chirila, O. Pyrolysis of lignin-a potential method for obtaining chemicals and/or fuels. Cellul. Chem. Technol. 2011, 45, 43-50.

7. Pittman, C.U., Jr.; Mohan, D.; Eseyin, A.; Li, Q.; Ingram, L.; Hassan, E.B.M.; Mitchell, B.; Guo, H.; Steele, P.H. Characterization of bio-oils produced from fast pyrolysis of corn stalks in an auger reactor. Energy Fuels 2012, 26, 3816-3825.

8. Mohan, D.; Pittman, C.U., Jr.; Steele, P.H. Pyrolysis of wood/biomass for bio-oil: A critical review. Energy Fuels 2006, 20, 848-889.

9. Zhang, M.; Resende, F.L.P.; Moutsoglou, A.; Raynie, D.E. Pyrolysis of lignin extracted from prairie cordgrass, aspen, and Kraft lignin by Py-GC/MS and TGA/FTIR. J. Anal. Appl. Pyrolysis 2012, 98, 65-71.

10. Patwardhan, P.R.; Brown, R.C.; Shanks, B.H. Understanding the fast pyrolysis of lignin. ChemSusChem 2011, 4, 1629-1636.

11. Shen, D.K.; Gu, S.; Luo, K.H.; Wang, S.R.; Fang, M.X. The pyrolytic degradation of wood-derived lignin from pulping process. Bioresour. Technol. 2010, 101, 6136-6146.

12. Sharma, R.K.; Wooten, J.B.; Baliga, V.L.; Lin, X.H.; Chan, W.G.; Hajaligol, M.R. Characterization of chars from pyrolysis of lignin. Fuel 2004, 83, 1469-1482.

13. Lou, R.; Wu, S.B.; Lv, G.J. Effect of conditions on fast pyrolysis of bamboo lignin. J. Anal. Appl. Pyrolysis 2010, 89, 191-196.

14. Wang, S.R.; Wang, K.G.; Liu, Q.; Gu, Y.L.; Luo, Z.Y.; Cen, K.F.; Fransson, T. Comparison of the pyrolysis behavior of lignins from different tree species. Biotechnol. Adv. 2009, 27, 562-567.

15. Obst, J.R. Analytical pyrolysis of hardwood and softwood lignins and its use in lignin-type determination of hardwood vessel elements. J. Wood Chem. Technol. 1983, 3, 377-397.

16. Pandey, M.P.; Kim, C.S. Lignin depolymerization and conversion: A review of thermochemical Methods. Chem. Eng. Technol. 2011, 34, 29-41.

17. Beis, S.H.; Mukkamala, S.; Hill, N.; Joseph, J.; Baker, C.; Jensen, B.; Stemmler, E.A.; Wheeler, M.C.; Frederick, B.G.; Heiningen, A.V.; et al. Fast pyrolysis of lignins. BioResources 2010 , $5,1408-1424$.

18. Nowakowski, D.J.; Bridgwater, A.V.; Elliott, D.C.; Meier, D.; de Wild, P. Lignin fast pyrolysis: Results from an international collaboration. J. Anal. Appl. Pyrolysis 2011, 88, 53-72.

19. Jiang, G.Z.; Nowakowski, D.J.; Bridgwater, A.V. A systematic study of the kinetics of lignin pyrolysis. Thermochim. Acta 2010, 498, 61-66.

20. Jakab, E.; Faix, O.; Till, F.; Szekely, T. Thermogravimetry/mass spectrometry study of six lignins within the scope of an international round robin test. J. Anal. Appl. Pyrolysis 1995, 35, 167-179.

21. Wang, J.; Zhang, M.X.; Chen, M.Q.; Min, F.F.; Zhang, S.P.; Ren, Z.W.; Yan, Y.J. Catalytic effects of six inorganic compounds on pyrolysis of three kinds of biomass. Thermochim. Acta 2006, 444, 110-114.

22. Amen-Chen, C.; Pakdel, H.; Roy, C. Production of monomeric phenols by thermochemical conversion of biomass: A review. Bioresour. Technol. 2001, 79, 277-299. 
23. Zakzeski, J.; Bruijnincx, P.C.A.; Jongerius, A.L.; Weckhuysen, B.M. The catalytic valorization of lignin for the production of renewable chemicals. Chem. Rev. 2010, 110, 3552-3599.

24. Lou, R.; Wu, S.B.; Lv, G.J. Fast pyrolysis of enzymatic/mild acidolysis lignin from moso bamboo. BioResources 2010, 5, 827-837.

25. Brebu, M.; Tamminen, T.; Spiridon, I. Thermal degradation of various lignins by TG-MS/FTIR and Py-GC-MS. J. Anal. Appl. Pyrolysis 2013, 104, 531-539.

26. Ben, H.; Ragauskas, A.J. NMR Characterization of Pyrolysis Oils from Kraft Lignin. Energy Fuels 2011, 25, 2322-2332.

27. Björkmann, A. Studies on finely divided wood. Part 1: Extraction of lignin with neutral solvents. Svensk Papperstidn 1957, 59, 477-485.

(C) 2015 by the authors; licensee MDPI, Basel, Switzerland. This article is an open access article distributed under the terms and conditions of the Creative Commons Attribution license (http://creativecommons.org/licenses/by/4.0/). 